\title{
Knowledge networks for adoption of additive manufacturing: The role of maturity
}

\author{
Anders Haug \\ University of Southern \\ Denmark \\ adg@sam.sdu.dk
}

\author{
Kent Adsbøll Wickstrøm \\ University of Southern \\ Denmark \\ kwj@sam.sdu.dk
}

\author{
Jan Stentoft \\ University of Southern \\ Denmark \\ stentoft@sam.sdu.dk
}

\author{
Kristian Philipsen \\ University of Southern \\ Denmark \\ kp@sam.sdu.dk
}

\begin{abstract}
Additive manufacturing (AM) has had a significant impact on manufacturing processes in many industries. The implementation of AM technology, however, involves several knowledge-related challenges, particularly for small and medium-sized enterprises (SMEs). We explore this topic by developing a theoretical model with the hypotheses that acquiring AM knowledge from networks is associated with competitive advantages from $A M$, and that this relationship can partly be explained by AM maturity. We test our model through a survey of Danish manufacturing SMEs. The findings show that AM knowledge acquisition from networks is positively associated with competitive advantages from AM, where around 40 percent of this relationship is explained by higher AM maturity. Furthermore, the findings suggest that different types of knowledge networks have different effects on AM maturity and competitive advantages from AM.
\end{abstract}

\section{Introduction}

Additive manufacturing (AM), informally known as "3D printing", describes a process of joining materials to make objects based on 3D models, typically through layer-by-layer joining of matter [2]. AM has had a significant impact on manufacturing processes in many industries in recent years, such as space, aerospace, automobile, medical and building industries $[10,18]$. Several types of benefits of AM technology have been reported, including higher product quality, increased innovation, shorter lead times, improved manufacturing flexibility, simpler supply chains, reduced warehouse needs, lower transportation costs, reduced assembly efforts, less waste, and reduced resource use [11, 26, 40, 47]. For such reasons, Wohlers [58] argued that AM's impact on manufacturing and supply chain management is likely to exceed all conventional methods put together.
The implementation of AM also involves several potential challenges, such as cost issues, low technical understanding, lack of operator skills, and unclearness about strategies for AM use $[13,14,26,33]$. To overcome challenges related to inadequate AM knowledge, firms may acquire this from external parties, such as consultants, research institutions, suppliers, and network organizations [53]. The acquisition of knowledge from such networks is, however, associated with costs and risks related to establishing, developing, and maintaining these $[37,59]$.

In this study, we focus on SMEs, as it appears that such firms have a greater need for acquiring external knowledge on AM. Specifically, research has shown that SMEs are often unaware of new manufacturing technologies and their benefits, implying that they are more hesitant to adopt these [15, 52]. Furthermore, when SMEs engage in AM, they often need to collaborate with external partners because of their lower levels of technological knowledge, capital, and strategic focus $[12,17,33,56]$. Establishing such relationships is, however, challenged by the lower bargaining power of smaller firms, which makes it harder to form long-term relationships and get support from manufacturing technology suppliers [35]. Thus, it has been argued that SMEs' approaches to AM implementation typically differ from larger companies [34].

Most research on AM adoption has been carried out with a focus on large companies or with mixed-sized samples without a particular SME focus (e.g., [12, 26, $34,40,42])$. It has, therefore, been argued that AM adoption in SMEs is poorly understood and that there is a need for more knowledge on AM adoption in SMEs [33]. To add to this knowledge, we investigate if acquiring AM knowledge from networks is associated with competitive advantages and if this may partly be explained by AM maturity. This is done by developing a theoretical model, which is tested through a survey of 157 Danish manufacturing SMEs. Furthermore, we analyze the role of the different network types in relation to competitive advantages from AM and AM maturity. 


\section{Literature and hypothesis development}

To understand the role of knowledge networks in relation to competitive advantages from AM, we draw on the knowledge-based view (KBV) of the firm [19, $20,29,51]$. KBV builds on the resource-based view of the firm, which conceptualizes firms in terms of resources that are the basis for their competitive position [57], but differs by emphasizing knowledge as a unique resource [29]. Specifically, KBV suggests that the creation of heterogeneous knowledge structures and capabilities across a firm is the main determinant of competitive advantages. Such knowledge resources are firm-specific and characterized by being difficult to transmit and imitate $[19,20]$.

A central element of $\mathrm{KBV}$ is knowledge integration ability, which, according to this theory, is central for competitiveness, as it allows a firm to integrate different knowledge streams, apply existing knowledge, and create new knowledge $[19,20]$. An important outcome of knowledge integration is a strategic alignment of business and technology [23, 46], which also holds for AM technology [34]. As an indicator of the extent of AM knowledge integration in the firm, we use the concept of AM maturity. Specifically, based on previous conceptualizations of maturity in relation to Industry 4.0, which includes AM (see [36]), we understand AM maturity as to how far in the development a firm is concerning its ability to utilize AM technology.

With a basis in the discussion above, we argue that AM knowledge acquired from external partners is associated with competitive advantages (H1). Next, we hypothesize that this relationship can partly be explained by higher levels of AM maturity, in the sense that the increase in competitive advantages from the use of knowledge networks is partly mediated by AM maturity (H2). This model is illustrated in Figure 1, after which its hypotheses are further explained.

Figure 1. Hypothesized model

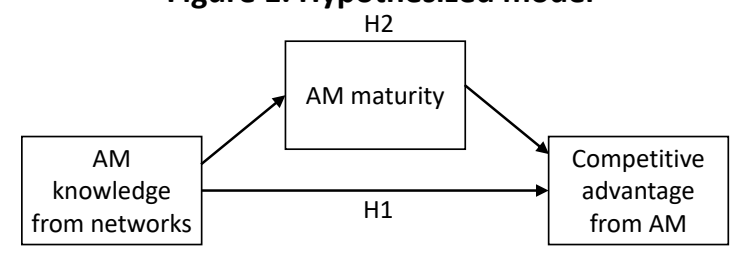

\subsection{The role of AM knowledge networks}

As mentioned in the introduction, there are many potential benefits of AM technology. These are, however, not easy to achieve, as illustrated by the many challenges to AM adoption described in the literature $[12,13,14,26,34,40]$. It could, however, appear that such challenges can be countered by the acquisition of knowledge from networks. To illustrate this point, in the following, we discuss the potential effects of knowledge acquisition with a basis in the $10 \mathrm{AM}$ barriers identified and ranked by Dwivedi et al. [14].

First, production technology barriers include material variety limitations [40] and issues related to strength, finish, performance, consistency, production speed, throughput rate, and part size [5, 6]. As such issues vary among different $\mathrm{AM}$ technologies, the acquisition of AM knowledge may support firms in choosing the AM technologies that suit their needs while avoiding potential problems associated with certain technology choices.

Next, the use of AM opens the door for IPR threats because of the ease at which illegally acquired digital models may be used to produce copies of products [6]. Furthermore, besides the theft of digital models, there is also the danger that parts are scanned and illegally produced [28]. This is linked to a need for government support for initiatives to help project firms against IPR violations [47]. Firms may mitigate such issues by acquiring knowledge on protecting digital models against theft and dealing with illegal scanning.

The next potential challenge of AM concerns that, as a consequence of the novelty and rapid development of AM technology, there is not a general understanding of the costs associated with the technology [34]. In this context, it has been pointed out that vendors may be aggressive when selling new technology and unwilling to disclose information that could weaken sales arguments, i.e., an "information asymmetry" [45]. Furthermore, firms often only have access to a limited number of AM vendors, giving these high negotiating power [40]. This produces a dependency on vendors, with whom negative experiences include issues with after-sales services, spare parts control, and communication [30]. Having knowledge about AM can mitigate the issue of information asymmetry with AM vendors, as well as the dependence on these. Specifically, the more the firms know about AM, the better they understand the costs associated with different AM technologies, allowing them to make better investments. Similarly, increased knowledge of AM puts the firm in a stronger position in relation to vendor selection and entering contracts with these.

The next potential challenge concerns the high costs associated with AM, which, although these have been significantly reduced in recent years, are still relatively high [40]. Besides the costs of AM machinery, there are also high maintenance costs of AM technology because of technology newness and the limited availability of service providers $[3,5,6]$. Through increased AM knowledge, firms may improve their basis for making decisions on AM investments and carry out part of the maintenance work themselves. 
For the successful implementation of advanced technologies, the literature generally agrees that management support is essential [3], which is also the case for AM technology [14]. The same goes for the employees, for which the use of AM technology can imply changes in job characteristics and work practices [34]. Such changes may lead to resistance against AM projects since workers are often reluctant to learn new technologies and change practices at which they excel, and because AM can reduce the dependency on manual labor [3]. The acquisition of knowledge about AM technology may reduce such reservations through more realistic perceptions of the changes that AM may produce and because these persons acquire AM competencies themselves.

The designers involved in the use of AM can also pose a challenge. Specifically, AM implies a need to design parts according to AM production capabilities, which limits the designers' "design freedom" and, therefore, may lead to resistance [34]. However, through the acquisition of AM knowledge, designers may let go of unwarranted reservations regarding the possibilities of the technology and identify ways to use AM that support their ideas.

With regard to the operation of AM, there is a need for skilled operators, for example, for tasks concerning part orientation, build volume maximization, and layering strategies [38]. However, finding suitable AM operators can be challenging [44]. In this context, retrieving knowledge on AM can increase in-house AM expertise, thereby reducing the need for hiring new staff.

Having discussed the ways in which the use of networks for acquiring AM knowledge may help firms overcome challenges associated with AM use, it should be emphasized that there are also some costs and risks related to the use of networks. Specifically, networks do not only work one way, but their benefits are connected to the level of resources invested [59]. In other words, for firms to acquire AM knowledge, they need to invest resources in building and maintaining such relationships.

One such relationship is with AM consultants. Specifically, since SMEs generally have more limited internal knowledge resources [25], they often use consultants as a source of technological expertise. The use of consultants is, however, often linked to high costs and does not necessarily involve much knowledge acquisition. As argued by Mueller and Dyerson [37], a firm may not be able to understand or properly evaluate the knowledge provided by consultants, which have "every incentive to utilize their knowledge strategically to build in dependency". Thus, this type of network involves the risk that a firm uses external consultants for handling their AM-related tasks instead of building internal AM knowledge.
Firms may also use other means to retrieve AM knowledge, such as business networks [53]. Although the costs of retrieving knowledge through such networks typically are lower, it may involve issues in the form of competition, conflict, strife, and disagreements that undermine the networks $[1,59]$. Furthermore, in relation to knowledge sharing between firms, there is also a chance of "free-riding" or "opportunism", which may imply that expected benefits are not achieved [31].

As the discussion above indicates, there are several ways in which the acquisition of AM knowledge through networks can positively influence the competitive returns of AM use, while there are also some costs and risks involved. Given the novelty and complexity of AM technology, together with the fact that SMEs typically lack technological expertise, we assume that the positive effects of acquiring knowledge from networks will outweigh the negative ones. This is, however, an assumption that needs to be investigated. Thus, we state the following hypothesis:

\section{H1: There is a positive association between networking for AM knowledge and competitive advantages from AM in SMEs.}

\subsection{The mediating role of AM maturity}

To explain the effects of acquiring knowledge from networks on competitive advantages, as described previously, we hypothesize that AM maturity has a mediating role in this relationship (i.e., an indirect effect). Specifically, with a basis in KBV, we assume that acquiring AM knowledge from networks supports the development of heterogeneous knowledge structures across the firm, which provide knowledge-based competitive advantage $[19,20,29,51]$. In this context, we argue that AM maturity is a suited indicator of if such organization-wide integration of AM knowledge has been achieved.

The concept of maturity is commonly used as a means for conceptualizing and measuring the progress of an organization or a process regarding some desired state [49]. In this context, AM maturity has been discussed under the "Industry 4.0" umbrella by several authors (e.g., [7, 36, 48, 49]). This literature defines maturity as a set of dimensions for evaluating a firm's level of maturity across business functions at strategic and operational levels (i.e., "maturity models").

Regarding the first part of the mediation relationship, it seems likely that the acquisition of AM knowledge through networks would positively affect a firm's AM maturity. Specifically, through the acquisition of AM knowledge, the firm may improve its ability to use AM strategically and operationally, as well as becoming more oriented towards doing so through a better understanding of the potential uses and benefits 
of AM. The latter part of the mediation relationship, i.e., AM maturity being positively associated with performance, is relatively uncontroversial. Specifically, since AM maturity describes a set of factors that defines a state associated with the ability to successfully apply AM technology, this type of relationship would be expected.

Based on the discussion above, we argue that the concept of AM maturity may help us understand the relationship between acquiring AM knowledge from networks and competitive advantages from AM. Specifically, we argue that knowledge acquisition from networks is associated with higher AM maturity, which is translated into competitive advantages. This is formulated as the following hypothesis:

H2: The positive association between networking for AM knowledge and competitive advantage is partly mediated by increasing AM maturity

\section{Research method}

\subsection{Data collection}

Our theoretical model was tested through a questionnaire survey of Danish manufacturing firms engaged in AM use. The focus on Danish firms was a result of funding constraints but may also be justified by the phenomenon of study. Specifically, Danish manufacturing firms are among the most technologically advanced in the OECD countries [41], making the sample well-suited for investigating the hypothesized model.

We decided to focus on firms with 20 to 250 employees, which were identified in the corporate databases Orbis and Bisnode (the latter claiming to include all Danish firms). From all the firms identified in the population, ones that were inactive or protected for advertisements were excluded. This produced a netlist of 1,166 firms, which were contacted through email about participating in the study. It was decided to use the companies' CEOs as respondents, and in cases where this was not possible, production or supply chain managers instead. 686 of the 1.166 companies replied to the email, implying a contact response rate of $58.8 \%$.

The email sent to the companies explained the purpose of the survey and asked them to answer whether: (1) the firm uses AM in the form of its own equipment or the use of print suppliers $(\mathrm{n}=216)$; (2) the firm is not using AM but are in an evaluation process about using it ( $\mathrm{n}=55)$; and (3) the firm does not use AM $(n=415)$. Of the 216 companies that were applying AM, 181 agreed to answer the questionnaire. These companies received a link via email to the web-based survey. Of these, 157 companies provided full answers, implying a response rate of $72.7 \%$ from the companies that applied AM. The firms in the sample, on average, had 70 employees and were 46 years old.

\subsection{Measures}

The dependent variable, "competitive advantage from AM", was measured by an index composed of three of the major dimensions of measuring manufacturing system performance, i.e., delivery time, production cost, and product quality [9]. Besides being firmly established in the literature, these dimensions are adequately broad to include most of the benefits mentioned in relation to AM use. In this context, respondents were asked to indicate on a five-point Likert scale how AM has contributed to competitive advantages in the form of a) reduced delivery times, b) more competitive prices, and c) improved quality. Factor analysis revealed one factor accounting for 60.1 percent of the total variance, and Cronbach's alpha for the index was .798 .

The independent variable, "AM knowledge retrieved from networks", was measured by an index asking respondents to indicate on a five-point Likert scale the extent to which they acquire AM knowledge from the following actors: a) AM consultants, b) research and education institutions, c) AM developers (hard- and software), d) AM suppliers, e) other AM users, and f) AM network organizations. These network types were identified in a previous study by the authors [53]. In the analysis, each of the network types was used as a separate variable and as part of a summative index.

The mediating variable, "AM maturity", was measured using the nine dimensions from the Industry 4.0 maturity model (hereunder AM) by Schumacher et al. [49], which is among the most established of its kind. Specifically, respondents were asked on a five-point Likert scale about their AM maturity in relation to the dimensions: strategy, leadership, customers, products, operations, culture, people, governance, and technology. Factor analysis revealed one factor accounting for 61.4 percent of the total variance, and Cronbach's alpha being .921, providing justification for the index. In general, the firms had moderate levels of AM maturity, on average scoring 2.41 on a scale from 1 to 5 , with values ranging from 1 to 4.78 .

We controlled for firm size and firm age, both of which have been linked to technology adaptation [4, 24]. To control for the influence of firms' networking being more or less concentrated in a few types of knowledge sources, we included a measure of network hierarchy. Hierarchy was measured using the ColemanTheil inequality index: $\sum_{j} r_{j} \ln \left(r_{j}\right) / N \ln (N)$ [8], where $r_{j}$ is the ratio of contact $j$ constraint over the average constraint, $c_{i j} /(\mathrm{C} / \mathrm{N})$, and $N$ is the number of 
contacts. Furthermore, we controlled for technological intensity using OECD's classification of four levels of industry intensity [16].

Questions and factor loadings for the main variables are shown in Appendix 1.

\subsection{Data analysis}

To assess the direct effect of acquiring knowledge from networks on competitive advantages from AM (H1) and the mediating effect of AM maturity (H2), we applied path analytical techniques implemented in Mplus 8.4 software [39]. Indirect effects were estimated using the Monte Carlo method to produce 95\% bootstrapped confidence intervals based on 2,000 random draws of the estimated sampling distributions of the estimates [50].

\section{Results}

Table 1 shows the means, standard deviations, and correlations among variables. To test for common method issues, we used Harman's single-factor test [22]. Results from the inclusion of all study items in a fixed one-factor un-rotated factor analysis explain only 32.86 percent of the total variance. This is well below the 50 percent recommended by Podsakoff et al. [43]. A fivefactor solution in comparison explains 63.78 percent of the total variance. These results indicate that common method bias should not be an issue. Furthermore, the results revealed that the variance inflation factor (VIF) values range between 1.07 and 2.11 , and tolerance values range between .47 and .94 . With VIF below 4.0 and tolerance higher than .2 , multicollinearity should not be a problem [21].

Table 1. Means, standard deviations, and correlations

\begin{tabular}{|c|c|c|c|c|c|c|c|c|c|c|c|c|c|c|}
\hline & Mean & Std.Dev. & 1 & 2 & 3 & 4 & 5 & 6 & 7 & 8 & 9 & 10 & 11 & 12 \\
\hline 1 Comp. Adv. & .000 & .770 & & & & & & & & & & & & \\
\hline 2 Netw. Cons. & 2.146 & 1.073 & $.338^{* *}$ & & & & & & & & & & & \\
\hline 3 Netw. Res\&Ed & 2.210 & 1.056 & $.189^{*}$ & $.436^{* *}$ & & & & & & & & & & \\
\hline 4 Netw. Develop & 1.809 & .893 & $.301^{* *}$ & $.331^{* *}$ & $.512^{* *}$ & & & & & & & & & \\
\hline 5 Netw suppliers & 2.395 & 1.148 & $.228^{* *}$ & $.432^{* *}$ & $.322^{* *}$ & $.537^{* *}$ & & & & & & & & \\
\hline 6 Netw. AM users & 2.503 & 1.164 & $.205^{*}$ & $.259^{* *}$ & $.404^{* *}$ & $.334^{* *}$ & $.287^{* *}$ & & & & & & & \\
\hline 7 Netw. Org & 2.274 & 1.164 & $.230^{* *}$ & $.250^{* *}$ & $.542^{* *}$ & $.341^{* *}$ & $.202^{*}$ & $.404^{* *}$ & & & & & & \\
\hline 8 Netw. Total & 2.223 & .746 & $.359^{* *}$ & $.652^{* *}$ & $.772^{* *}$ & $.713^{* *}$ & $.670^{* *}$ & $.663^{* *}$ & $.673^{* *}$ & & & & & \\
\hline 9 Hierarchy & .129 & .015 & -.030 & $-.183^{*}$ & $-.304 * *$ & $-.301 * *$ & -.040 & .070 & -.080 & $-.189 *$ & & & & \\
\hline 10 AM Maturity & .000 & .856 & $.550^{* *}$ & $.219^{* *}$ & 0.046 & $.316^{* *}$ & $.318^{* *}$ & $.173^{*}$ & $.244^{* *}$ & $.354^{* *}$ & .067 & & & \\
\hline 11 Size & 70.025 & 52.416 & -.072 & .057 & .042 & .070 & .046 & .002 & .003 & .051 & $-.199 *$ & -.043 & & \\
\hline 12 Age & 46.420 & 25.904 & .105 & .025 & -.034 & .142 & -.003 & -.103 & .069 & .017 & .010 & .144 & $.208^{* *}$ & \\
\hline 13 Techn. Int. & 2.688 & .799 & .070 & .001 & .093 & .015 & -.012 & .142 & .092 & .083 & -.116 & $.160 *$ & .077 & -.150 \\
\hline
\end{tabular}

Next, the results from the path analysis, using the summative index of the different network types, are shown in Table 2. As seen, there is a significant positive association between AM maturity and competitive advantage $(.463, \mathrm{p}<.000)$. The results also show a significant positive association between networking and AM maturity $(b=.298, \mathrm{p}<.000)$. Furthermore, both the direct and the total effect of networking on competitive advantage are significant and positive $(b=.193, p<.000 ; b=.332, p<.000)$, and they do not contain zeroes in the confidence intervals. This supports $\mathrm{H} 1$ of a positive association between AM networking and competitive advantages from AM. The indirect effect is also significant and positive $(b=.138, p<.000)$, hence supporting $\mathrm{H} 2$ that part of the total effect from AM networking occurs as a learning effect, where networking increases SMEs' AM maturity, which in turn increases competitive returns from AM. As seen, the indirect effect accounts for approximately 40 percent of the total effect from AM networking.
Finally, Table 3 shows the results from knowledge networking with the individual actors. As seen, there is a significant positive total effect on SMEs' competitive advantage from networking with AM consultants $(b=.198, p=.008)$, AM developers $(b=p=.009)$, and other AM users $(b=.169, p=.046)$, while there are no zeroes in the confidence intervals. For AM consultants and other AM users, the direct effects are significant and positive $(b=.142, p=.038$; $\mathrm{b}=.144, \mathrm{p}=.031$ ), and they do not contain zeroes in their confidence intervals. Yet, their indirect effects are insignificant $(b=.056, p=.165 ; b=.025, p=.523)$ and contain zeroes in the confidence intervals. This indicates that the learning effects from networking with AM consultants and other AM users are weak and that other kinds of returns are present.

On the other hand, significant positive indirect effects are found in knowledge networking with AM developers $(b=.099, \quad \mathrm{p}=.001)$ and network organizations $(b=.105, p=.002)$, while marginally significant effects are found for AM suppliers $(b=.073$, $\mathrm{p}=.074)$. Zero is not contained in the confidence 
interval for any of these. It is noticeable that for AM network organizations and suppliers, the total effects are not significant, and the variables' coefficients for the direct effects are negative. This slightly attenuates the presence of some other liabilities associated with these relationships.

Surprisingly, the results show a significant negative indirect effect from networking with research and education institutions $(b=-.142, p=.001)$, not containing zero in the confidence interval. This negative effect is particularly driven by a significant negative association between networking with research and educational institutions and AM maturity.

Table 2. Direct, indirect, and total effects of total network on competitive advantage

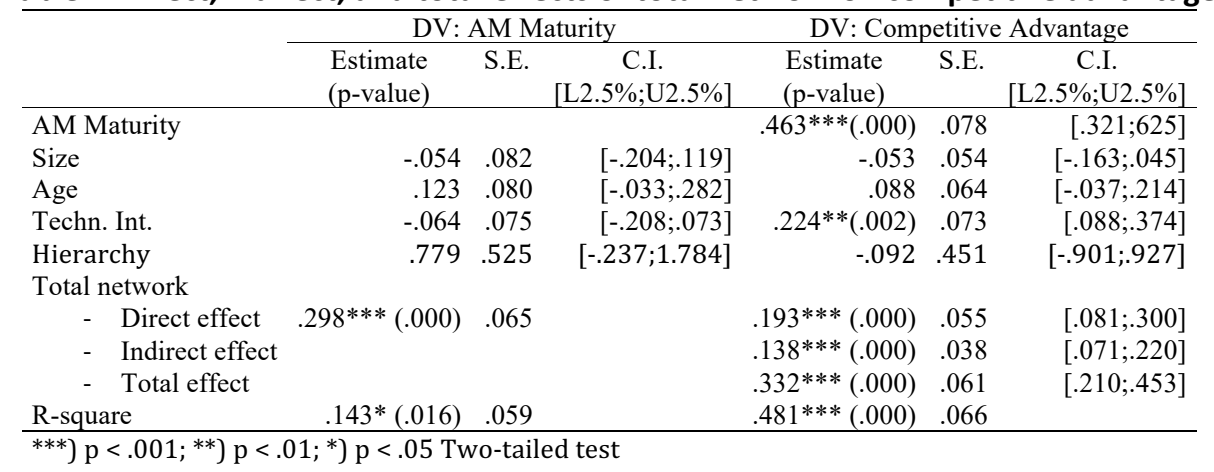

Table 3. Direct, indirect, and total effects of different networks on competitive advantage

\begin{tabular}{|c|c|c|c|c|c|c|c|c|c|}
\hline & \multicolumn{3}{|c|}{ Direct effect } & \multicolumn{3}{|c|}{ Indirect effect } & \multicolumn{3}{|c|}{ Total effect } \\
\hline & $\begin{array}{l}\text { Estimate } \\
\text { (p-value) }\end{array}$ & S.E. & $\begin{array}{c}\text { C.I. } \\
{[\mathrm{L} 2.5 \% ; \mathrm{U} 2.5 \%]}\end{array}$ & $\begin{array}{l}\text { Estimate } \\
\text { (p-value) }\end{array}$ & S.E. & $\begin{array}{c}\text { C.I. } \\
{[\mathrm{L} 2.5 \% ; \mathrm{U} 2.5 \%]}\end{array}$ & $\begin{array}{l}\text { Estimate } \\
\text { (p-value) }\end{array}$ & S.E. & $\begin{array}{c}\text { C.I. } \\
{[\mathrm{L} 2.5 \% ; \mathrm{U} 2.5 \%]}\end{array}$ \\
\hline Netw. Consultants & $.142 *(.038)$ & .068 & {$[.004 ; .275]$} & $.056(.165)$ & .037 & {$[-.013 ; .152]$} & $.198 * *(.008)$ & .074 & {$[.049 ; .336]$} \\
\hline Netw. Res\&Edu & $-.008(.929)$ & .043 & {$[-.197 ; .168]$} & $-.142 * *(.001)$ & .043 & {$[-.243 ;-.069]$} & $-.150(.107)$ & .092 & {$[-.351 ; .018]$} \\
\hline Netw. Developers & $.165+(.012)$ & .095 & {$[-.016 ; .360]$} & $.099 * *(.006)$ & .036 & {$[.033 ; .177]$} & $.264 * *(.009)$ & .100 & {$[.070 ; .464]$} \\
\hline Netw Suppliers & $-.098(.212)$ & .078 & {$[-.258 ; 050]$} & $.073+(.074)$ & .041 & {$[.004 ; .167]$} & $-.025(.777)$ & .088 & {$[-.202 ; .153]$} \\
\hline Netw. AM users & $.144 *(.031)$ & .067 & {$[.018 ; .279]$} & $.025(.523)$ & .039 & {$[-.044 ; .112]$} & $.169 *(.046)$ & .079 & {$[.014 ; .347]$} \\
\hline Netw. Org & $-.051(.476)$ & .072 & {$[-.197 ; .090]$} & $.105^{* *}(.002)$ & .034 & {$[.046 ; .183]$} & $.054(508)$ & .081 & {$[-.122 ; .208]$} \\
\hline R-square & $.522 * * *$ & .065 & & & & & & & \\
\hline
\end{tabular}

\section{Discussion}

As described in the previous section, the findings supported our hypotheses that the use of external knowledge networks is positively associated with increased competitive advantages from AM and that this relationship can partly be explained by increasing AM maturity (around 40 percent). Thus, our findings extend $\mathrm{KBV}$ to an AM context by indicating that the integration of AM knowledge is reflected in firms' AM maturity, which is associated with competitive advantages.

Interestingly, the results suggest that different types of knowledge networks have different effects on both AM maturity and competitive advantages from AM. To explain these effects, in the subsequent discussion, we also consider the potential role of AM maturity in relation to the types of networks utilized for acquiring knowledge. This connects with KBV in the sense that the development of the AM-related knowledge and capabilities across the firm, which AM maturity reflects, could influence which knowledge resources are considered valuable and utilized.

The results showed that the acquisition of knowledge from AM consultants and other AM users is positively associated with competitive advantages, whereas not with higher AM maturity. In this context, attention may be drawn to the types of consultants in focus, i.e., AM consultants helping the firms to operate AM technology, as opposed to, for example, business consultants hired to facilitate organizational transformation. As previously discussed, it is typically not in the interest of consultants to make themselves superfluous, for which reason they may keep certain knowledge to themselves [37], thus, not significantly improving AM maturity. The other way around, it should be considered that the use of AM consultants is a means to compensate for the lack of internal AM expertise, which could suggest that it is mainly firms with lower AM maturity that utilize this approach. There seems to be a similar picture regarding the retrieval of knowledge from other AM users, which is mainly associated with less AM mature firms. This may be 
explained by the nature of such knowledge resources, which is likely to be relatively general, as opposed to being based on insights from close collaboration.

The acquisition of AM knowledge from AM developers (hard- and software), on the other hand, is not directly associated with competitive advantages but indirectly through increased AM maturity. A possible explanation for the increase in maturity concerns the advanced AM expertise possessed by these, which they, to some extent, may share with the firm during development processes. The other way around, it could be expected that it is only SMEs with a certain level of maturity that initiate costly AM software and hardware development projects.

Next, the results showed that retrieving knowledge from network organizations neither has a significant direct or total effect on competitive advantages from AM but an indirect effect. This pattern indicates that suppression is taking place [32], i.e., intermediate mechanisms in the association between networking with AM network organizations and SMEs' competitive advantages from AM, which are not accounted for in the model. Specifically, such mechanisms may be canceling out the positive effect mediated by increased AM maturity. To explain this, we may turn the focus to what a network organization is. Specifically, network organizations provide news about AM, a forum for firms to exchange AM knowledge, sparing and counseling, and AM machines that may be used against a fee [53]. Thus, there are several reasons why AM network participation would be linked to AM maturity. On the other hand, the use of network organizations' AM machines may provide some explanation of the lack of competitive advantages from using this type of network. Specifically, using AM machines offered by network organizations, as compared to in-house AM, has some consequences: (1) higher costs per 3D print for higher volumes; (2) longer waits for 3D prints; and (3) the use of standard AM machines, as opposed ones customized to the needs of the individual firm.

Surprisingly, not only did we not find significant direct or total effects of the acquisition of knowledge from research and educational organization, but even a significant negative indirect effect. A nearby explanation is that the knowledge provided by universities is too theoretical and of limited practical relevance $[54,55]$. This, however, may rather explain a lack of positive effects than negative ones. Thus, another explanation concerns that it is mainly SMEs with low AM maturity that engages with research and educational institutions as a first step in developing their AM competencies - and only when they get further along their learning path, they commit more resources and engage with more professional AM actors. A third possible explanation concerns that SMEs, through collaboration with research and educational organizations, encounter ideal models and best cases for AM, making them realize that they have more room for improvements than initially believed. Thus, such firms may score themselves lower than their counterparts with similar AM maturity.

Finally, retrieving AM knowledge from suppliers is not significantly linked to direct or total effects on competitive advantages, and an effect on AM maturity was only significant in the $90 \%$ confidence interval. This absence of more significant effects may be explained by the focus of the suppliers, i.e., to sell AM equipment, which may limit the extent to which firms can use these as a source of knowledge [45]. There is, however, a slight indication that more AM mature firms retrieve knowledge through such networks.

\section{Conclusions}

The present study investigated the role of acquiring AM knowledge from networks in relation to obtaining competitive advantages from AM. This was done through a survey of 157 Danish manufacturing SMEs. First, we found that the acquisition of knowledge from networks is positively associated with competitive advantages from AM, thereby confirming our first hypothesis. Next, we investigated if the relationship between acquisition of knowledge from networks and competitive advantages from AM to some extent could be explained by increasing AM maturity, i.e., a mediation effect. This second hypothesis was also confirmed with AM maturity explaining around 40 percent of the relationship. To further explain these findings, we analyzed the role of the individual network types. This analysis showed that there were competitive advantages of retrieving knowledge from AM consultants and other AM users, which, however, were not linked to increased AM maturity. On the other hand, AM maturity explained the relationship between retrieving knowledge from AM developers (hard- and software) and competitive advantages. The remaining network types did not yield significant positive effects.

\subsection{Research implications}

This paper provides two main contributions to the AM literature. First, with a basis in the knowledgebased view of the firm, the paper developed and tested a theoretical model that explains the role of AM maturity in the relationship between AM knowledge acquisition from networks and competitive advantages from AM. We, thereby, connect the concepts of AM maturity and knowledge networking in the context of competitive advantages from AM. Second, the findings 
indicate that different levels of AM maturity are associated with different networks for retrieving AM knowledge. Specifically, our findings suggest that different network types have different effects on AM maturity and that, as firms gain AM maturity, they utilize different networks for retrieving knowledge.

Through these contributions, the present study extends existing research on the adoption and use of AM technology (e.g., [6, 26, 34, 40]. Furthermore, the study provides new knowledge on technology adoption in SMEs (e.g., [15, 17, 35, 52], in particular, it contributes to the sparse knowledge on AM adoption in SMEs [33, 53].

\subsection{Implication for practice}

The findings suggest that firms engaging in AM should utilize their networks for acquiring knowledge, as this endeavor is positively associated with competitive benefits from AM. However, it appears that not all networks are equally beneficial. Specifically, our findings suggest that consultants and other AM users are most beneficial for firms with low AM maturity, while more mature firms benefit from acquiring knowledge from developers of AM hardware and software. Another implication is that firms initiating AM use should attempt to increase their AM maturity, which the study links to greater competitive advantages from AM use.

\subsection{Limitations and future research}

An important limitation is the cross-sectional nature of the study. Thus, we do not know if the use of knowledge networks described by the respondents has changed over time. In this context, the relative novelty of AM technology to some extent may mitigate this issue. Nevertheless, future research may conduct longitudinal studies to provide a better understanding of the causal relationships involved.

Another limitation concerns that data was retrieved from a single respondent in each firm, which may be associated with respondent bias. In this context, the significance of implementing AM in manufacturing firms suggests that CEOs and supply chain managers would be involved in such matters. This argument is further supported by the study's focus on SMEs, for which previous studies indicate that top managers tend to be involved in such issues $[15,17,33,52]$. In this context, deeper insights into the role of AM maturity in relation to the use of knowledge networks may be obtained through qualitative studies.

A third limitation concerns the use of perceptual measures in relation to $\mathrm{AM}$ knowledge acquisition intensity, AM maturity, and AM's effect on performance. Regarding the respondents' ability to make such evaluations, the top managers' proximity to daily operations in SMEs [15, 17, 33, 52] and the significance of AM investments could suggest that such managers would have a reasonable impression of these factors. In relation to the relativity of such measures, we recognize that comparing ratings across individual firms would be problematic. On the other hand, given the focus of the questions, it appears unlikely that firms in the low and high end in those regards would be unaware of that. Nevertheless, the present hypotheses need to be investigated in future studies to provide additional support for the present findings.

\section{References}

[1] Anderson, E., and S.D. Jap, "The dark side of close relationships", MIT Sloan Management Review 46(3), 2005, pp. 75-82.

[2] ASTM, F2792-12a: Standard Terminology for Additive Manufacturing Technologies, ASTM International, West Conshohocken, PA, 2012.

[3] Baldwin, J., and Z. Lin, "Impediments to advanced technology adoption for Canadian manufacturers", Research Policy 31(1), 2002, pp. 1-18.

[4] BarNir, A., J.M. Gallaugher, and P. Auger, "Business process digitization, strategy, and the impact of firm age and size: The case of the magazine publishing industry", Journal of Business Venturing 18(6), 2003, pp. 789-814.

[5] Baumers, M., P. Dickens, C. Tuck, and R. Hague, "The cost of additive manufacturing: Machine productivity, economies of scale and technology-push", Technological Forecasting and Social Change 102, 2016, pp. 193-201.

[6] Berman, B., "3-D printing: The new industrial revolution”, Business Horizons 55(2), 2012, pp. 155-162.

[7] Bibby, L., and B. Dehe, "Defining and assessing industry 4.0 maturity levels: Case of the defence sector", Production Planning \& Control 29, 2018, pp. 1030-1043

[8] Burt, R.S. (1992). Structural Holes, Harvard University Press, Cambridge, MA.

[9] Chen, K.S, and M.L. Huang, "Performance measurement for a manufacturing system based on quality, cost and time", International Journal of Production Research 44(11), 2006, pp. 2221-2243.

[10] Chen, Y., Y. Wang, S. Nevo, J. Benitez, and G. Kou, "Improving strategic flexibility with information technologies: Insights for firm performance in an emerging economy", Journal of Information Technology 32(1), 2017, pp. 10-25.

[11] Delic, M., and D.R. Eyers, "The effect of additive manufacturing adoption on supply chain flexibility and performance: An empirical analysis from the automotive industry", Journal of Production Economics, 2020, Article 108087.

[12] Deradjat, D., and T. Minshall, "Implementation of rapid manufacturing for mass customisation", Journal of 
Manufacturing Technology Management 28(1), 2017, pp. 95-121.

[13] Ding, J, M. Baumers, E.A. Clark, and R.D. Wildman, "The economics of additive manufacturing: Towards a general cost model including process failure", International Journal of Production Economics, 2021, Article 108087.

[14] Dwivedi, G., S. Srivastava, and R. Srivastava, "Analysis of barriers to implement additive manufacturing technology in the Indian automotive sector", International Journal of Physical Distribution \& Logistics Management 47(10), 2017, pp. 972-991.

[15] Fulton, M., and B. Hon, "Managing advanced manufacturing technology (AMT) implementation in manufacturing SMEs", International Journal of Productivity and Performance Management 59(4), 2010, pp. 351-371.

[16] Galindo-Rueda, F., and F. Verger, "OECD Taxonomy of Economic Activities Based on R\&D Intensity", OECD Science, Technology and Industry Working Papers, OECD, Brussel, 2016.

[17] Ghobakhloo, M., and N.T. Ching, "Adoption of digital technologies of smart manufacturing in SMEs", Journal of Industrial Information Integration 16, 2019, online publication 100107.

[18] Gibson, I., "The changing face of additive manufacturing", Journal of Manufacturing Technology Management 28(1), 2017, pp. 10-17.

[19] Grant, R.M., "Prospering in dynamically-competitive environments: Organizational capability as knowledge integration", Organization Science 7, 1996, pp. 375-387.

[20] Grant, R.M., "Toward a knowledge-based theory of the firm", Strategic Management Journal 17,1996, pp. 109122.

[21] Hair, J. F., R.E., Anderson, B.J. Babin, and W.C. Black, Multivariate Data Analysis: A Global Perspective" (7th ed.), Prentice Hall, Englewood Cliffs, NJ, 2010.

[22] Harman, D., A single factor test of common method variance, Journal of Psychology 35, 1967, pp. 359-378.

[23] Henderson, J.C., and N. Venkatraman, "Strategic alignment: Leveraging information technology for transforming organizations", IBM Systems Journal 32(1), pp. 4-16, 1993.

[24] Horváth, D., and R.Z. Szabó, "Driving forces and barriers of Industry 4.0: Do multinational and small and mediumsized companies have equal opportunities?", Technological Forecasting and Social Change 146, 2019, pp. 119-132.

[25] Hussin, H., M. King, P.B. Cragg, "IT alignment in small firms", European Journal of Information Systems 11(2), 2002, pp. 108-127.

[26] Ituarte, I.F., S. Khajavi, and J. Partanen, "Challenges to implementing additive manufacturing in globalised production environments", International Journal of Collaborative Enterprise 5(3/4), 2016, pp. 232-247.
[27] Jonsson, P., and J. Holmström, "Future of supply chain planning: Closing the gaps between practice and promise", International Journal of Physical Distribution \& Logistics Management 46(1), 2016, pp. 62-81.

[28] Kietzmann, J., L. Pitt, and P. Berthon, "Disruptions, decisions, and destinations: Enter the age of 3-D printing and additive manufacturing", Business Horizons 58(2), 2015, pp. 209-215.

[29] Kogut, B., and U. Zander, "Knowledge of the firm, combinative capabilities and the replication of technology", Organization Science 3, 1992, pp. 383-397.

[30] Laosirihongthong, T., H. Paul, and M.W. Speece, "Evaluation of new manufacturing technology implementation: An empirical study in the Thai automotive industry", Technovation 23(4), 2003, pp. 321-331.

[31] Lui, S.S., Y.Y. Wong, W. Liu, "Asset specificity roles in interfirm cooperation: Reducing opportunistic behavior or increasing cooperative behavior?", Journal of Business Research 62(11), 2009, pp. 1214-1219.

[32] MacKinnon, D.P., J.L. Krull, C.M. Lockwood, "Equivalence of the mediation, confounding and suppression effect", Prevention Science 1, 2000, pp. 173181.

[33] Martinsuo, M., and T. Luomaranta, "Adopting additive manufacturing in SMEs: Exploring the challenges and solutions", Journal of Manufacturing Technology Management 29(6), 2018, pp. 937-957.

[34] Mellor, S., L. Hao, and D. Zhang, "Additive manufacturing: A framework for implementation", International Journal of Production Economics 149, 2014, pp. 194-201.

[35] Mishra, R., "A comparative evaluation of manufacturing flexibility adoption in SMEs and large firms in India", Journal of Manufacturing Technology Management 27(5), 2016, pp. 730-762.

[36] Mittal, S., M.A. Khan, D. Romero, and T. Wuest, "A critical review of smart manufacturing \& Industry 4.0 maturity models: Implications for small and mediumsized enterprises (SMEs)", Journal of Manufacturing Systems 49, 2018, pp.194-214.

[37] Mueller F., R. Dyerson, "Expert humans or expert organizations?", Organization Studies 20(2), 1999, pp. 225-256.

[38] Munguía, J., J. de Ciurana, and C. Riba, "Pursuing successful rapid manufacturing: A users' best-practices approach", Rapid Prototyping Journal 14(3), 2008, pp. 173-179.

[39] Muthén, B., and L. Muthén, Mplus User's Guide (8th ed.), Muthén and Muthén, Los Angeles, CA, 2017.

[40] Niaki, M.K., and F Nonino, "Impact of additive manufacturing on business competitiveness: A multiple case study", Journal of Manufacturing Technology Management 28(1), 2017, pp. 56-74. 
[41] OECD (2017). OECD Science, Technology and Industry Scoreboard: The Digital Transformation, OECD Publishing, Paris, France.

[42] Oettmeier, K., and E. Hofmann, “Additive manufacturing technology adoption: An empirical analysis of general and supply chain-related determinants", Journal of Business Economics 87(1), 2017, pp. 97-124.

[43] Podsakoff, P.M., S.B. MacKenzie, and N.P. Podsakoff, "Sources of method bias in social science research and recommendations on how to control it", Annual review of psychology 63, 2012, pp. 539-569.

[44] PwC, "3D Printing comes of age in US industrial manufacturing", 2016, available at: http://www.pwc.com/us/en/industrial-products/3dprinting-comes-of-age.html.

[45] Rahman, A.A. and D. Bennett, "Advanced manufacturing technology adoption in developing countries: The role of buyer supplier relationships", Journal of Manufacturing Technology Management 20(8), 2009, pp. 1099-1118.

[46] Reich, B.H., and I. Benbasat, "Factors that influence the social dimension of alignment between business and IT objectives", MIS Quarterly 24(1), 2000, pp. 81-113.

[47] Rogers, H., N. Baricz, and K.S. Pawar, "3D printing services: Classification, supply chain implications and research agenda", International Journal of Physical Distribution \& Logistics Management 46(10), 2016, pp. 886-907.

[48] Schuh, G., R. Anderl, J. Gausemeier, M. ten Hompel, and W. Wahlster, Industrie 4.0 Maturity Index: Managing the Digital Transformation of Companies, Herbert Utz Verlag, Munich, Germany, 2017.

[49] Schumacher, A., S. Erol, and W. Sihn, "A maturity model for assessing Industry 4.0 readiness and maturity of manufacturing enterprises", Procedia CIRP 52, 2016, pp. 161-166

[50] Selig, J.P., and K.J. Preacher, "Monte Carlo method for assessing mediation: An interactive tool for creating confidence intervals for indirect effects" [Computer software], 2008, available at: http://quantpsy.org.

[51] Spender, J.C., "Making knowledge the basis of a dynamic theory of the firm", Strategic Management Journal 17, 1996, pp. 45-63.

[52] Stentoft, J., K.W. Jensen, K. Philipsen, and A. Haug, "Drivers and barriers for Industry 4.0 readiness and practice: Empirical evidence from small and mediumsized manufacturers", Production Planning \& Control 32(10), 2021, pp. 811-828.

[53] Stentoft, J., K. Philipsen, A. Haug, and K.A. Wickstrøm, "Motivations and challenges with the diffusion of additive manufacturing through a non-profit association", Journal of Manufacturing Technology Management 32(4), 2021, pp. 841-861.
[54] Stentoft, J. and C. Rajkumar, "Balancing theoretical and practical relevance in supply chain management research", International Journal of Physical Distribution \& Logistics Management 48(5), 2018, pp. 504-523.

[55] Tether, B.S., "Who co-operates for innovation, and why: An empirical analysis, Research Policy 31(6), 2002, pp. 947-967.

[56] Thomas, A.J., R. Barton, and E.G. John, "Advanced manufacturing technology implementation: A review of benefits and a model for change", International Journal of Productivity and Performance Management 57(2), 2008, pp. 156-176.

[57] Wernerfelt, B., "A resource-based view of the firm", Strategic Management Journal 5(2), 1984, pp. 171-180.

[58] Wohlers, T. (2016), Wohlers Report 2016, Wohlers Associates, Fort Collins, CO, 2016.

[59] Yang, Z., Z. Huang, F. Wang, and C. Feng, "The doubleedged sword of networking: Complementary and substitutive effects of networking capability in China", Industrial Marketing Management 68, 2018, pp. 145155 .

\section{Appendix 1. Questions and factor loadings}

The following items were all measured on a five-point LikertScale: $1=$ to a very low degree, and $5=$ to a very high degree

AM knowledge from networks

To which extent do you acquire knowledge from

the following actors?

a) AM consultants

b) Research and education institutions

c) AM hard- and software developers

d) AM suppliers

e) Other AM users

d) AM network organizations

Competitive advantages from AM

\begin{tabular}{lr}
\hline To which extent has the use of AM technology produced & Load. \\
the following competitive advantages? & \\
a) Reduced delivery times & .719 \\
b) More competitive prices & .817 \\
c) Improved product quality & .787 \\
\hline Total variance explained (\%) & 60.14 \\
Cronbach's Alpha & .82 \\
\hline
\end{tabular}

AM maturity

How mature is your use/implementation of AM in the Load. following areas?

a) AM is a strategic focus area $\quad .797$

b) We have the right AM leadership 837

c) AM is a conscious choice to develop customer solutions $\quad .802$

d) AM is a conscious choice to develop the product program $\quad .768$

e) AM is tailored to our operations $\quad .816$

f) We have the right AM culture $\quad .825$

g) We have the right AM employees $\quad .719$

h) We work using the right standards for AM use $\quad .763$

i) The AM technologies used is among leading ones $\quad .716$

Cronbach's Alpha $\quad .92$ 